\section{Silvia}

Barona

Vilar

\section{Universitat}

València

Directora del

Grupo MedArb y

Proyecto Excelencia

Prometeo 2018/111

silvia.barona@uv.es

Recibido: 10.05.19

Aceptado: 07.06.19

\title{
Cuarta revolución industrial (4.0.) o ciberindustria en el proceso penal: revolución digital, inteligencia artificial y el camino hacia la robotización de la justicia*
}

\section{Fourth industrial revolution (4.0.) Or cyber- industry in the criminal process: digital revolution, artificial intelligence and the path towards the robotization of justice}

Resumen: El objetivo de este trabajo es analizar la irrupción de la cuarta revolución industrial (4.0.) y sus consecuencias, especialmente la inteligencia artificial, en la justicia en general, y en la penal en particular. La incorporación de sistemas de expertos, algoritmos y modelos computacionales en el asesoramiento, predicción y toma de decisiones judiciales es ya una realidad. Se avizora una inquietante situación con la posibilidad de la robotización judicial o el juez robot (máquina inteligente) en sustitución del juez persona, que crea una cognición artificial que plantea dudas acerca de la individualización de la pena, de la posible responsabilidad de la máquina, la sensibilidad de víctimas especialmente vulnerables o grupos deprimidos, la ética, la afectación de derechos de las personas, la fiabilidad, etc.

Palabras clave: Inteligencia artificial; justicia penal; robotización judicial.
Abstract: This paper aims to analyze the irruption of the fourth industrial revolution (4.0.) and its consequences, especially Artificial Intelligence, in Justice, particularly in Criminal Justice. The incorporation of expert systems, algorithms and computational models in counseling is now a reality, as well as in predicting and in legal decisions. The incorporation of judicial robotic or robot-judge (machine learning) represents a disturbing situation. The replacement of the human-judge creates an artificial cognition that raises doubts about ethics, reliability, the individualization of the sanction, the possible responsibility of the machine, the sensitivity of especially vulnerable victims or depressed groups, the violation of the people's rights, etc.

Keywords: Artificial Intelligence; Criminal Justice; Judicial robotization

* Este trabajo se realiza en el marco del Proyecto de excelencia PROMETEO GV 2018/111 (Claves de la Justicia Civil y Penal). 
Especialmente en las últimas décadas la tecnología ha ido paulatina pero imparablemente transformando nuestras vidas. Y lo ha hecho con tal intensidad, que ha ido propiciando la aparición de la denominada cuarta revolución industrial en la que se vino asimilando el mundo digital con la inteligencia artificial, la blockchain y la robótica.

Esta Cuarta Revolución Industrial llega en un momento histórico, político y económico, como sucediera en las tres revoluciones industriales anteriores: la primera, que revolucionó la industria con la máquina de vapor (en la década de los años 1760), que impulsó la mecanización agrícola y la producción textil, así como la producción de embarcaciones y ferrocarriles a través de la energía de vapor, que favoreció la aparición de una clase trabajadora específica, que propulsó la conformación de las ciudades y de su industria y economía más desarrollada en torno a estas. La segunda, que vino de la mano de los avances en la ciencia y la producción masiva (a partir de 1900), favorecida por la electricidad, la aparición de los motores de gasolina, los aviones, los descubrimientos de la física y de la química (en el sector agrario fueron importantes los fertilizantes químicos), que impulsaron el método científico y favorecieron las plataformas de producción masiva. La tercera Revolución Industrial se alimentó de la computación y de las tecnologías digitales (especialmente a partir de la década de 1950 debido a la aparición de la microelectrónica, de los mainframes y de las primeras apariciones de la inteligencia artificial). La sociedad analógica fue dando paso poco a poco al mundo digital, con la aparición del internet y la transformación digital, que favoreció el impulso de mejora de los procesos operativos empresariales, amén de generar nuevos modelos de negocio.

Hablar de las diversas revoluciones industriales es referirse a cambios profundos y transformaciones sociales que no fueron resultado de un instante $\mathrm{O}$ momento específico, sino una metamorfosis de la vida, de la comunicación, del trabajo, de la economía, del paisaje, etc. que favoreció la transformación evolutiva de las sociedades eminentemente agrícolas a las ciudades o, si se quiere, de la vida rural a la vida urbana, en las que se introducían nuevas maneras de configurar la vivienda, la vida, las relaciones interpersonales y laborales, de estructurar la política y de favorecer el bienestar social y la evolución de los pueblos. En esa evolución, la introducción de la mecánica, de la electricidad, de la producción en masa, de los medios de comunicación y transporte, fueron avances que impregnaron la sociedad moderna, si bien la revolución digital ha supuesto una revolución imparable, de alta velocidad, masiva, transformadora social, que está alterando los soportes y principios esenciales que permitieron la construcción de la sociedad moderna. Una sociedad basada, diseñada y estructurada desde y con la tecnología; una sociedad en la que ocupan lugares privilegiados las redes sociales, la nube, el internet de las cosas (IoT), la inteligencia artificial, los vehículos autónomos, la impresión 3D, la nanotecnología, la biotecnología, el big data, la machine learning, el deep learning, y un largo etcétera que nos encaminan hacia un mundo inteligente, un mundo que se despliega desde un internet mucho más móvil y mundial, por sensores más pequeños y más potentes, y por inteligencia artificial u aprendizaje automático, lo que cambia con ello la forma de vivir, trabajar y relacionarnos los unos con los otros (Schwab, 2018, p. 13).

La cuarta revolución industrial o del 4.0. comporta la digitalización de las cadenas a través de la tecnología de procesamiento de datos, software inteligente y sensores que facilitan la actividad, desde los que pueden trabajar fabricantes, proveedores, distribuidores, clientes y consumidores para poder predecir, controlar, planear y producir de forma inteligente, lo que favorece un sistema productivo global. Es innegable que su impronta se muestra esencialmente en el sector económico, y especialmente en cuanto tenga vinculación con la previsión, producción, comercialización y distribución de bienes y productos, con su extensión de forma imparable al sector de servicios. Un modelo económico eficiente, a menor coste y en menor tiempo. Es más, un modelo económico que se expande, penetra y se solidifica en todos los ámbitos de la vida, no solo en la producción, comercialización o consumo. 


\section{De la globalización al pensamiento económico y su alcance en la justicia}

Es innegable que la cuarta revolución industrial se presenta como una consecuencia derivada de la globalización, un periodo de progresiva pero imparable transformación de espacios, de protagonistas, de valores, etc., o, como apunta Stegler, como un

conjunto multidimensional de procesos sociales que crea, multiplica, despliega e intensifica intercambios e interdependencias sociales en el nivel mundial, a la vez que crea en las personas una conciencia de conexión cada vez mayor entre lo local y lo distante (Stegler, 2003, p. 13).

En ese escenario el modus operandi de gestión industrial ha penetrado en la sociedad, las costumbres y la vida misma. Una vida "conectada" tecnológicamente, de manera que la temporal "inconexión" se percibe como aislamiento, exilio del mundo social en que vivimos. Y esa nueva manera de afrontar la vida en general y la consolidación de los valores en particular, se encuentra inspirada en un claro pensamiento económico, un razonamiento que transporte desde el lenguaje económico los grandes disvalores de la sociedad actual, la eficiencia y la eficacia, midiéndose todo desde el criterio del coste-beneficio.

Los conceptos económicos se han instalado en todos los estamentos y ámbitos de nuestra vida. Basta pensar en los términos que empleamos en nuestra actividad cotidiana, de ser competitivos, la importancia del liderazgo, el retorno que se obtiene por una determinada actividad, la excelencia en el desempeño de una misión, el valor del éxito, la rentabilidad que se obtiene, la optimización de resultados o las políticas estratégicas que debemos desempeñar, entre otras. Son todos ellos componentes de nuestro lenguaje cotidiano porque, lejos de ser palabras vacuas, reflejan una manera de afrontar las relaciones cualesquiera fuere su naturaleza. Muy probablemente este paisaje se produce como consecuencia de la ubicación de la producción y el consumo como los ejes que mueven no solo el crecimiento económico, sino el mundo.

Un pensamiento que ya encontró un soporte institucional en la conformación de la Escuela de Chicago (Plant, 2016, pp. 75-98), desde la que se defendía la minimización del Estado en la economía, o lo que es lo mismo, dejando al mercado que fluya y decida, siendo el Estado el que debía garantizar la libre competencia, estimulándola en todo caso; un estímulo que se entendía debía encontrar su soporte en la sublimación de la eficiencia.

1.1. Eficacia y eficiencia: una pequeña aclaración conceptual

Trabajar con los criterios - elevados a la categoría de valores - de la eficacia y la eficiencia nos mueve a tratar de aclarar ambos términos. Su integración conceptual podría permitirnos afirmar que significan obtener resultados reales y hacer más con menos, lo que permite un ahorro de recursos y una mejora de los resultados.

Eficaz supone ser capaz de obtener resultados satisfactorios en cantidad y calidad, mientras que eficiente se es cuando se logran esos resultados satisfactorios sin utilizar más recursos que los necesarios.

Hemos venido apuntando que los criterios de eficacia y eficiencia están elevados a la categoría de los grandes disvalores de la sociedad actual, por cuanto permiten valorar, equilibrar y favorecer la toma de decisiones en cualquiera de los ámbitos de la vida. Eso significa que también el mundo de la justicia, sin obviar la justicia penal, está siendo "reinterpretado" desde esos dos contrapesos y, obviamente, con consecuencias jurídicas innegables.

\subsection{Eficacia y eficiencia en la justicia}

Las fuentes de inspiración de las nociones y principios del derecho han sido diversas de las que pudieren mover el mundo económico. Ha sido en ese tsunami de la 
globalización cuando ha empezado a reinterpretarse el derecho desde una visión economicista, en la que mucho tuvo que ver la construcción del Análisis Económico del derecho al que se refiriera en su día la Escuela de Chicago.

La eficiencia y la eficacia en la justicia se muestran en la actualidad como incentivos de reformas, como presupuestos de financiación de instituciones, como criterios de decisiones políticas en materia de justicia. De este modo se habla de la necesidad de conjugar ambos, también para ofrecer la "debida" justicia que los ciudadanos necesitan.

Por un lado, la justicia es eficaz si se imparte a quienes la demandan (hay respuesta a la ciudadanía) y si las respuestas que se ofrecen a través de las resoluciones judiciales que se dictan son de calidad. A estos efectos son diversos los indicadores que nos permiten analizar si la justicia es realmente eficaz. Es posible considerar los asuntos que ingresan al año en sede judicial, aquellos que son resueltos y aquellos que quedarían en trámite; y, por su parte, habría que considerar la duración de los procesos (tiempo empleado para ofrecer la respuesta) y las causas que pueden concurrir para ello, de modo que habrá que ponderar la duración de los procesos con posibles situaciones que puedan darse como consecuencia de coordenadas exponenciales específicas, tales como una situación de crisis económica como la vivida en años anteriores, que inundaron de demandas los juzgados y colapsaron determinadas sedes judiciales. Se trataría de considerar, a estos efectos, los momentos coyunturales, que no estructurales, que pudieren alterar los indicativos antes apuntados y que podrían generar, en términos economicistas, un desbordamiento de la capacidad del sistema o diferencias palmarias de productividad.

Por otro lado, la justicia es eficiente si obtiene unos resultados proporcionales a los recursos que la sociedad pone a su disposición. La eficiencia se centra en la evaluación de la relación entre los recursos empleados y los resultados obtenidos. Y se toman como indicadores de esta evaluación los recursos humanos que se emplean, los presupuestos que se aplican para el desarrollo de las actuaciones y funciones, sin olvidar la posibilidad de que concurran ciertos desajustes que alteren o modifiquen los resultados de la valoración de los indicadores anteriormente expuestos.

Se considera, por ende, que el modelo de justicia es eficaz cuando contribuye a que la sociedad disfrute de las ventajas de la justicia como derecho y como pilar del Estado. Y se presenta el mismo como eficiente si todo ello se logra con un coste razonable, lo que lleva a considerar que los males de la justicia son, a este respecto, la lentitud, la carestía y la predictibilidad.

1.3. Algunas medidas para alcanzar esa eficacia y esa eficiencia en la justicia penal

La aplicación de los indicadores expuestos puede llevar a considerar que la justicia penal no es todo lo eficaz o todo lo eficiente que debiera y es por ello que se considera que pudiera ser adecuada la adopción de medidas específicas para alcanzarlas. Una mirada a las legislaciones de nuestro entorno jurídico permite observar que los males de la justicia penal son casi universales y se muestran las deficiencias en unos países con más intensidad que en otros, empero se presenta un paisaje con una gran uniformidad en cuanto a las posibles medidas que se van adoptando en los diversos sistemas jurídicos nacionales.

Es por ello, en consecuencia, que a modo de ejemplo, podemos apuntar algunas de las más populares medidas que se han venido incorporando en la mayor parte de los países:

1. En primer lugar, las reformas procesales penales han sido una constante. La necesidad de cambiar modelos procesales penales fue lo que originó el primer paso y, poco a poco, los sistemas jurídicos procesales penales se encaminaron hacia una construcción desde el principio acusatorio, inspirador de los principios esenciales y garantistas del proceso penal (presunción de inocencia, derecho de defensa, derecho al silencio, prueba y garantías, publicidad, inmediación, etc.), que afectó también a sus protagonistas y sobre todo a su manera de hacer justicia.

Esas reformas legislativas procesales se han ido sucediendo de forma constante e imparable y de forma universal en todos los sistemas jurídicos, a la búsqueda 
de soluciones que permitan paliar uno de los males de la justicia, la lentitud. Es por ello que hemos venido asistiendo a una reformulación de los procedimientos en aras de alcanzar una mayor abreviación en su tramitación (Barona, 2017).

2. En segundo lugar, se ha producido un cambio de modelo que ha arrastrado, por un lado, un cambio de protagonistas, favoreciendo un mayor papel de la Policía y del Ministerio Público. No se trata de trasladar sin más funciones judiciales a estos protagonistas, que ya existían en la esfera procesal penal anterior, sino de reforzar algunas de las que tenían, atribuyéndoles la persecución penal, amén de fortalecer su capacidad de gestión de la misma.

Este cambio de protagonistas ha exigido una capacitación de los mismos para el ejercicio de sus funciones o, lo que es lo mismo, ha habido que fortalecer sus estatutos e incorporar procesos de preparación para la adquisición de nuevas herramientas en el ejercicio de la función. La prolija sectorialización de la Fiscalía y de la Policía muestra ese grado de preparación y de formación que se viene desplegando en la búsqueda de una mejor justicia para todos los ciudadanos.

3. En tercer lugar, el modelo procesal penal diseñado en la impronta de la modernidad, basado en el principio de legalidad estricto y en el ejercicio del ius puniendi del Estado, que llevaba a la puesta en marcha del aparato judicial tan pronto se tuviere noticias de la posible existencia de la comisión de un hecho delictivo, se ha visto poco a poco modulado. Esta modulación no implica, en absoluto, la conversión en un proceso dispositivo, empero sí la incorporación paulatina en la mayor parte de los sistemas jurídico-procesales de manifestaciones del principio de oportunidad.

Ciertamente, la incorporación de estas manifestaciones no ha estado exenta de polémica, manteniendo posiciones enfrentadas. Caso especialmente significativo fue la Strafprozessordnung alemana, dado que, si bien se aceptaba en la realidad judicial la existencia de consensos y conformidades (Absprache), el legislador se resistía a reconocer en la norma procesal la eficacia jurídica de los mismos. La profusa incorporación de estas manifestaciones del principio de oportunidad ha supuesto la aceptación de acuerdos, pactos y consensos entre la Fiscalía y el imputado-acusado con consecuencias procedimentales -abreviaciones y terminacionesasí como procesales - delimitando el contenido de las sentencias a través de la conformidad-. Y hoy en día puede afirmarse, sin duda, que las manifestaciones de oportunidad forman parte de la Justicia penal, lo que favorece las abreviaciones procedimentales a través de la voluntad de aceptar la consecuencia jurídicopenal solicitada por la parte acusadora. Con estas conformidades, los acusados salen beneficiados porque su comportamiento repercute en una reducción de pena; los jueces y fiscales resuelven una causa sin complejidad y el sistema lo agradece al reducirse los costes, la duración del proceso y se evita el recurso contra la sentencia de conformidad.

4. Inevitablemente, cuando se habla de la eficacia y la eficiencia de la justicia penal debemos hacer referencia a la necesidad de aumento en cantidad y calidad de los recursos humanos. Por un lado, la complejidad de las relaciones personales y sociales ha llevado a una multiplicación de asuntos, lo que requiere mayor capital humano para responder a las demandas y a las causas que se generan como consecuencia de estas. Pero no solo se exige mayor número de jueces, fiscales, policía y personal judicial, sino que también se hace necesario que todos ellos puedan actuar con la mejor calidad posible, lo que enlaza directamente con la exigencia de capacitación de los mismos. La buena formación y la adquisición de herramientas necesarias para saber desarrollar sus funciones, de acuerdo con los roles establecidos, son absolutamente necesarias para que el sistema procesal y judicial funcione.

5. La justicia penal está mostrando desde hace varias décadas una mirada diversa en relación con las víctimas. Si durante mucho tiempo fue la gran olvidada, la ausente del sistema penal, desde hace varias décadas, movimientos como la victimología, la criminología crítica, el feminismo, el realismo jurídico, etc., han venido abogando por una necesaria recuperación de la misma y su presencia en el modelo procesal penal. De hecho, las legislaciones han venido atribuyéndole siquiera el derecho de información en el proceso, amén de favorecer 
una mirada restaurativa, incorporando cada vez más mecanismos de justicia restaurativa en el sistema penal.

Si bien es cierto que el fundamento y justificación de esta necesidad restaurativa se asienta en las razones expuestas, la búsqueda de la eficiencia y eficacia también han calado, en ciertos casos, en ese interés político e ideológico por favorecer la incorporación de modelos restaurativos, especialmente la mediación penal, un procedimiento instrumental que, aun cuando con esa vocación filosófica restitutiva o restaurativa, permite otorgar al delincuente la posibilidad de responder ante las víctimas, responsabilizándose de la reparación, entendida esta en sentido maximalista, a saber, reparación económica o dineraria, material o devolución de cosa o bien, prestación de servicio como trabajo social o en beneficio de la víctima (sea individual o colectiva), así como la aceptación incluso de un protocolo de actuación relacional de presente y futuro cuando se trata de víctimas y victimarios que tienen una relación permanente y duradera (personal, familiar, laboral, vecinal, asistencial, etc.).

En suma, se pretende que la mirada restaurativa incorpore esa vocación de transformación a la que se refirió uno de los padres de la justicia restaurativa, John Braithwaite, quien consideraba que estamos ante un "camino para transformar el sistema legal en su conjunto, nuestro estilo de vida, nuestra conducta en el ámbito laboral y la manera de actuar de los políticos" (Braithwaite, 2003, p.1), lo que llevó a este autor a considerar que con ella se pretende actuar frente a lo que denomina como injusticia preventiva. Es por ello, a mi parecer, que la mediación penal (Barona, 2011) y las otras manifestaciones de la justicia restaurativa se convierten en una bocanada de aire fresco en un contexto en que vivimos en el que el control, la prevención, la seguridad ciudadana, la securitización, la desconfianza hacia el otro emerge y se apodera de las relaciones. Es por ello que la incorporación de la justicia restaurativa se muestra, por un lado, como mecanismo de aceptación en el sistema penal de la función restaurativa o reparadora y, en segundo lugar, la aceptación de que, además del proceso, pueden incorporarse al sistema vehículos de canalización de esta función, como sucede con la mediación, virando los protagonistas de la justicia, dando protagonismo en este procedimiento al binomio presunta víctima y presunto autor. Abrir la puerta a la comunicación, al diálogo, al reconocimiento del otro (bilateral), a las posibilidades de reconsideración del mundo penal y la búsqueda de la integración, que no disgregación, solo puede merecer nuestro apoyo y nuestra confianza en el sistema. Merece, cuanto menos, su consideración en esta sociedad descreída, con la economía como elemento inspirador, con falta de asideros, vacua, desmotivada y desilusionada (Barona, 2017, pp. 606-607 y 614).

Estas modalidades de tutela restaurativa no solo ofrecen una mirada diversa de la justicia, una manera distinta de mostrar la justicia, sino que, igualmente, se percibe por los políticos como una manera de favorecer la visión eficiente del sistema en su conjunto. Si el procedimiento de mediación finaliza con acuerdo y este se incorpora al proceso penal, este, el proceso, necesariamente experimenta un acortamiento y un resultado final que vendrá marcado por la experiencia en mediación, a saber, pudiendo llegarse al archivo de la causa o a una sentencia que incorpore el acuerdo y la consecuencia jurídica pertinente, pero que afecta a la duración del proceso, al trabajo de los protagonistas de la justicia y por ello a las arcas del Estado.

6. Finalmente, en ese mundo global de economización de la vida y la sociedad, emergen con una impronta absoluta las tecnologías y su imbricación también con los avances de la ciencia. $Y$ todo ello repercute en el mundo de la justicia. Son múltiples las acciones que se vienen observando, como la pausada pero imparable incorporación de la justicia electrónica (eJustice) que, más allá de la configuración del expediente electrónico, supone la aceptación de la tecnología como cauce o medio de realización de actos procesales, incluida la incorporación de las pruebas electrónicas, las notificaciones electrónicas, las resoluciones judiciales electrónicas, y la propulsión de la neurociencia en sede de investigación penal para favorecer mediante técnicas propias la búsqueda de la verdad desde la investigación científica, con el fin de concluir la verdadera culpabilidad o no del sospechoso-imputado, el grado de reincidencia que puede implicar una persona, la veracidad de los testigos o peritos, etc. 
Y a todo ello debe añadirse igualmente la expansión de las tecnologías inteligentes, como componente de la ya conocida cuarta revolución industrial. Estas tecnologías indudablemente, y lejos de pensar en un sobrecoste de la justicia, conllevan una previsión de liquidez y liquidación de muchos obstáculos, trámites de procedimiento y personas que intervienen en el mismo, y es indudable que son tremendamente aceptadas por quienes diseñan el modelo de sociedad tecnificada, conectada, vinculada a las redes electrónicas, que proyectan la denominada "energía inteligente" a través del internet y las tecnologías, favoreciendo la adaptabilidad de las necesidades que aparecen y todo ello comporta una indiscutible asignación más eficiente de los recursos. En este sentido, basta pensar en las nuevas nociones incorporadas en nuestro día a día y en el ámbito de la justicia, tales como el software inteligente, la digitalización de documentos, procesamiento de datos, y un largo etcétera de conceptos que reflejan esa percepción.
Todos ellos implican ese cambio de modus operandi que ofrece también en sede de la justicia la búsqueda de la maximización y la obtención de beneficios (Hobsbawm, 2012, p. 134).

Lógicamente, el paso de las tecnologías básicas a la sofisticación tecnológica también está llegando al mundo de la justicia, incorporando la inteligencia computacional y, desde ella, revolucionando las maneras de actuar, sus protagonistas y su pensamiento. Su implementación se integra en la revolución industrial del 4.0. y en la conversión de la nueva vida digital que se alimenta cada vez más de la inteligencia artificial y de la máquina inteligente. Hay que luchar para que estos avances se desplieguen como servicio al ser humano y no al revés, o lo que es lo mismo, que se presenten como herramientas que permitan lograr un futuro más próspero y confortable, más igualitario y humano, más solidario y más justo. Por ende, sirvan a la justicia para ser más justa.

\section{Robotización también en la justicia}

En ese paisaje que hemos ido presentando de la cuarta revolución industrial han ido emergiendo los instrumentos del mundo digital, internet y tecnologías, se han generado plantas industriales encaminadas a propulsar la energía inteligente y a diseñar un mundo que favorece y presenta una enorme "fábrica inteligente" que extiende sus tentáculos de forma global y expansiva al mundo jurídico y también a la justicia penal. Desaparecen fronteras físicas, el mundo analógico quedó catapultado y se expande una nueva manera de concebir la justicia en general, la penal en particular y el modus operandi en el proceso penal en especial. Curiosamente, las utopías imaginativas mostradas en obras como 1984 de George Orwell o El informe de la minoría de Philip K. Dick que dio lugar a la famosa película de Steven Spielberg en 2002, Minority Report, en las que se refleja una sociedad bajo las tecnologías del control; expresan algo a lo que asistimos en estos momentos en la sociedad actual.
2.1. El 4.0., la inteligencia artificial y la robotización en el mundo jurídico

En el escenario jurídico, la industria inteligente no solo ha penetrado, sino que encuentra un campo de cultivo con un largo e interesante recorrido.

En la medida en que las tecnologías forman parte de nuestras relaciones jurídicas (basta pensar en los actos de consumo que realizamos, en el sector de servicios, en la compra de bienes como alimentos, ropa, libros, para nuestras actividades de ocio como billetes de transporte, reservas de hoteles, actos de consumo bancario que nos llevan a hacer transferencias bancarias, a gestionar pagos online y un largo etc.), es coherente pensar que, paralelamente, se van conformando mecanismos de gestión y solución de conflictos con los mismos instrumentos. 
Podemos dar algún ejemplo como la aparición de la red privada de comunicaciones denominada EUFides, un canal telemático que permite a las empresas y a los particulares realizar operaciones transnacionales con su notario de confianza (una red notarial que es instrumental para favorecer la circulación de documentos), ofreciendo, en consecuencia, seguridad jurídica preventiva a las sociedades y particulares que realizan actividades transfronterizas. Y también las tecnologías han favorecido una nueva manera de violar normas, de cometer infracciones y hasta de cometer delitos; no en vano esa "hiperconectividad" ha llevado también a la "cibercriminalidad". Obviamente esto ha propulsado una era de "ciberseguridad" como estrategia, incluso precisamente, para salvaguardar los datos personales y la información, que casa a la perfección con la cuarta revolución industrial.

La fascinación por la celeridad y la eficiencia (más con menos) que presenta el mundo jurídico actual han propiciado una transformación de una justicia escrita, lenta, analógica y presencial en un modelo ágil, oral, tecnológico y digital. Y es en esas coordenadas en las que se ha venido favoreciendo la incubación de esta cuarta revolución industrial o lo que se denomina el 4.0. industrial, la Industria Inteligente de la justicia o la Ciberindustria de la justicia del futuro, dado el implacable y penetrante mundo de las TICs en la justicia que nos lleva a plantearnos más allá de su uso instrumental, la posibilidad de que la cuarta revolución industrial (4.0.) -nueva manera de organizar los medios de producciónllegue también a la toma de decisiones judiciales y se haga realidad la "justicia-máquina perfecta".

En un primer estadio llegó la eJustice, y se incorporaron los procedimientos electrónicos paulatinamente. Poco a poco, sin embargo, la energía digital se ha colado también en la justicia, propulsando una manera de gestionar lo procesal desde parámetros diversos en los que la funcionalidad, la agilidad, la economía y la eficiencia son valores que priman en su desenvolvimiento. Más allá de esa manera digital procedimental de funcionar, se pretende avanzar hacia la incorporación de la IA y de la machine learning, también en el mismo ejercicio de la función jurisdiccional, tanto como complemento, como juez-robot; cuestión esta a la que nos referiremos infra.
En el mundo jurídico son ya múltiples las manifestaciones que encontramos que han absorbido una manera diversa no solo de concebir las relaciones, sino también de gestionarlas, de adquirir herramientas, de obtener servicios, de buscar respuestas legales de asesoramiento, gestión, solución de conflictos y un largo etcétera. Podemos en este sentido considerar la red mundial World Wide Web (www), para buscar información jurídica, que se nutre necesariamente de un lenguaje jurídico que cada vez más trata de uniformarse para ser más eficiente; o el empleo de los sistemas de Legal Advisory Systems o sistemas de asesoría jurídica; o los sistemas de Legal Decision Support Systems, que ofrecen apoyo a la predictibilidad del posible resultado de una controversia jurídica; los sistemas de argumentación y de negociación jurídicas, entre otros. Todos ellos han venido incorporando una suerte de inteligencia artificial aplicada al mundo legal. En este sentido, cabe igualmente citar la "Jurimetría", o el análisis de precedentes jurisprudenciales dentro de una óptica conductista aplicada a la informática jurídica, de manera que traduce (convierte) el lenguaje jurídico en lenguaje simbólico de las matemáticas y la lógica, y con ello permite realizar estadísticas jurídicas, estrategias de comunicación e incluso de defensa. En suma, permite incorporar una enorme dosis de previsibilidad de éxito o fracaso en sede judicial, con análisis estadístico de jueces, magistrados, juzgados, tribunales y asuntos que en ellos se han venido conociendo, determinando.

2.2. Su aplicabilidad en la investigación criminal, el proceso penal y la ejecución penal

El proceso penal ha venido experimentando una enorme transformación en las últimas décadas. El mundo electrónico y digital ha favorecido la conformación de los componentes electrónicos (eJustice) que, si bien no se aplican de forma uniforme y en todo el iter procedimental, sí que han ido permitiendo la incorporación de las tecnologías en la investigación y en el proceso en la fase probatoria. $Y$ en esta fase es posible no solo considerar los informes y documentos electrónicos, sino también la agilidad que ofrece el empleo de las tecnologías en la práctica de determinados medios de prueba, como puede ser el que se ofrece a través del empleo de las videoconferencias en el juicio oral. $Y$ ello sin que sea posible considerar que quedan afectadas las garantías 
de determinados actos del proceso, sino que antes al contrario, se ha conseguido evitar en muchos casos dilaciones innecesarias o torticeras.

Ahorabien, el camino continúa. En elámbito de lajusticia penal, la cuarta revolución industrial no solo ha permitido el progreso positivo sino que ha incorporado nocivas consecuencias de su empleabilidad, como es la facilidad con la que la delincuencia ha traspasado fronteras, ha roto espacios territoriales y ha propiciado una gran debilidad del Estado global. La delincuencia que se comete a través de internet no entiende de fronteras, de modo que acrecienta, ante la desaparición de límites espaciales, nuevos riesgos y específicas responsabilidades. Esa complejidad existe indudablemente y es fruto de la penetración de las TICs en la vida cotidiana, que trascienden al mundo del derecho y especialmente al derecho penal. Esto ya no preocupa solo a los Estados sino muy especialmente al mundo empresarial, que se mueve desde parámetros digitales y requiere fomentar esa ciberdefensa para tratar de minimizar los riesgos cibernéticos. El mundo digital se expande y con él el espacio, la comunicación, la economía y el derecho, y en todo este nuevo mundo digital de relaciones diversas y peculiares, también la infracción de las normas y la comisión de delitos se puede efectuar a través de los instrumentos digitales, generando una realidad jurídica absolutamente desconocida hasta hace unos años y tremendamente exitosa en la agilidad y rapidez de sus movimientos.

En el contexto descrito, los Estados se han mostrado en muchas ocasiones inoperantes, no solo por falta de inadecuación de sus normas, sino porque los medios de persecución de estas infracciones y delitos requerían de una adaptación a esta realidad virtual y a este mundo digital. La cooperación judicial entre Estados, los movimientos interregionales y la capacitación de los protagonistas de persecución penal y de investigación han sido los grandes retos de estas últimas décadas. Las tecnologías no solo deben jugar a favor de la comisión de hechos delictivos o de su sofisticación, sino también a favor de la más ágil, rápida y efectiva investigación criminal, amén del mismo desarrollo del modelo procesal penal, ya sea en sede de juicio oral o ya en ejecución de sentencia.
Podemos citar, a este respecto, la interconexión que las tecnologías permiten entre la Policía, el Ministerio Público y los tribunales de justicia, favoreciendo las actuaciones procesales, la investigación y facilitando la cooperación no solo entre órganos directamente vinculados con el Poder Judicial, sino incluso con la Hacienda Pública, el sistema bancario, la Seguridad Social, etc. La cooperación nacional e internacional en la lucha contra el crimen ha experimentado una efectividad exponencial debido al desarrollo de las tecnologías, que permiten en tiempo real esa colaboración, y no solo entre órganos judiciales sino que alcanza a los servicios policiales y de inteligencia, que ven en las tecnologías medios mucho más ágiles y efectivos en la persecución de hechos singulares, de organizaciones criminales y, también, en la prevención de las conductas delictivas.

Igualmente, a título de ejemplo, se ha aplicado como sistemas de control (a través de algoritmos) que permiten detectar rostros, identificar personas a través del iris, la huella dactilar, los movimientos, y un largo etcétera, que no solo juegan a efectos de persecución de la delincuencia, sino que abrigan opciones preventivas de control que se dirigen a mantener una seguridad y un orden social o colectivo. En esa evolución de las máquinas al servicio de la investigación criminal se han incorporado realidades que hace tan solo unos pocos años eran impensables, como, entre las más modernas e impactantes, la denominada tecnología del reconocimiento facial, que permite identificar a personas en una foto o captada en una cámara de seguridad. Ciertamente, se argumenta que la tecnología de reconocimiento facial viene con la promesa de mayor seguridad, si bien se aproxima más bien al escenario orwelliano de una sociedad de sometidos al control de no se sabe muy bien quién o qué. Podría permitir identificar a personas que lleven velo, pasamontañas, gafas, máscaras, etc. Se trata, en suma, de algoritmos, de técnicas de análisis de datos y de creación de bancos de imágenes de caras que entregan a las fuerzas de seguridad un instrumento para identificar a delincuentes, terroristas, etc.

Estos mecanismos, indudablemente, y así hay que afirmarlo, limitan, cuando no minimizan o restringen, los derechos y garantías que los ciudadanos poseen en 
el contexto social que vivimos. Una sociedad que bajo el paraguas del miedo y la inseguridad evoca políticas públicas, no se sabe si voluntariamente o impulsada por los medios de comunicación, la prensa amarilla y los políticos mismos; políticas públicas que tienen un objetivo finalista claro: el control, la prevención, la seguridad o si cabe la securitización de la sociedad moderna (Barona, 2018, pp. 138-144).

También en sede de ejecución penal o como medida cautelar, es posible pensar en las denominadas pulseras electromagnéticas que permiten establecer un control de la persona allá donde se encuentre, por ejemplo, si se le exige que no puede salir de una determinada demarcación o que, por el contrario, tiene prohibido acudir a un determinado lugar o acercarse a una determinada persona. La pulsera es el instrumento en virtud del cual se puede llevar a cabo ese control, de forma electrónica, en sede policial, sin necesidad de tener que llevar detrás un control policial que efectivamente constate la movilidad permitida o prohibida de la persona.

Ahora bien, el avance de las tecnologías en sede procesal penal, empero, continúa, y lo hace con avances realmente espectaculares en la función judicial de toma de decisiones, ora favoreciendo la simplificación del razonamiento a través de la incorporación de criterios, ora llegando a incorporar las máquinas inteligentes a los efectos de alcanzar la sustitución del juez por la máquina o, lo que es lo mismo, ofrecer la robotización judicial o el juez-robot. A estos avances dedicamos las páginas siguientes.

2.3. De las Sentencing Guidelines a la Judicial Machine o juez-robot

No hay duda alguna de que la tecnología ha avanzado y lo ha hecho lo suficiente como para favorecer el ejercicio de la función jurisdiccional, el razonamiento lógico jurídico que llevaría a valorar los hechos aportados al proceso, la prueba de los mismos, las circunstancias concurrentes, todo para producir el fallo. Esa función puede verse notablemente favorecida por el empleo de las tecnologías, sin perjuicio de que la última palabra jurídica sería de los jueces humanos. Cuestión diversa es la aplicación de la tecnología no como complemento sino como sustituto del juez. A estos dos niveles de aplicación de las nuevas tecnologías en el sistema procesal penal, vamos a referirnos a continuación y vendrían a ser dos variantes de la inteligencia artificial, con unas consecuencias jurídico-procesales diversas de las que hemos venido tratando en las páginas anteriores.

\subsubsection{Sistema de expertos: Sentencing Guidelines,} Mandatory Penalities y sistemas de predictibilidad

Las ya existentes y consolidadas modalidades de sistemas de expertos que se han ido desarrollando en EE. UU., nos permiten contar con un banco de pruebas suficiente para detectar que estos sistemas ya no son un experimento jurídico, sino que ofrecen respuestas en la toma de decisiones judiciales en la justicia norteamericana. Decisiones judiciales que se van gestando con la colaboración de unos criterios que juegan como guías a la hora de la toma de decisiones. Y estos criterios, que nacieron inicialmente con vocación experimental o potestativa, se fueron paulatinamente convirtiendo en criterios que constreñían los sentidos de las sentencias judiciales.

Este primer sistema que permite trabajar con reglas o estándares que favorecen el sentido de las sentencias se ofrecía para paliar algunos de los grandes males de la justicia, a saber, la ausencia de predictibilidad y la eficiencia del modelo procesal, para evitar retardaciones y generar mayor certidumbre en la ciudadanía. Indudablemente, estos dos componentes merman ineludiblemente la capacidad decisoria del juez, cercenando el razonamiento lógico deductivo desplegado en la formulación de la sentencia. Se trata, en suma, de incorporar unos estándares o criterios que permiten fijar el sentido de la sentencia y, sobre todo, en atención a los mismos, la gravedad de la condena que se imponga.

En este sistema de expertos es posible incardinar lo que surgió en EE. UU. bajo la denominación de las sentencing guidelines, destinadas a lograr una cierta uniformidad en las decisiones judiciales. Iniciado de forma voluntaria en Denver y Vermont por algunos jueces, como proyecto piloto, fue paulatinamente aceptándose en otros Estados como Maryland, Florida, Massachusetts, Michigan, New Jersey, Utah y Wisconsin. Con esas primeras acciones se favoreció igualmente la aprobación en California de 
la Determinate Sentencing Act (California Penal Code $\$ 1170$ (a) (I)) en 1976. En todos ellos concurría un objetivo: configurar unos criterios que permitieran eliminar la disparidad y favorecer la uniformidad de las condenas. Se trataba de reglas numéricas, orientadoras y, como tal, voluntarias, lo que significaba que los jueces podían apartarse de ellas, aunque para ello tuvieren que motivar su separación.

Progresivamente, estos criterios, que nacieron con vocación de potestatividad, se convirtieron en normas compulsivas en los diversos estados americanos a partir de los años ochenta, hasta que en 1987 se aprobaron las US Sentencing Guidelines (U.S.S.G.), tras la Sentencing Reform Act 1984. Se diseñaron unos sistemas numéricos (Richrich, Sutton, Clear \& Saks, 1982), que incorporaban tablas con criterios tanto para condenar y absolver como para, en el caso de condena, fijar la gravedad de la misma. Entre los criterios se encontraban el género, el estatus social, la situación laboral, la edad, la raza, el estado civil, etc., y se favorecía especialmente un endurecimiento punitivo de determinadas personas que, por edad, raza, género y clase social, resultaban prejuiciadas en relación comparativa con otras. Los posibles resultados de la aplicación de estos sistemas numéricos alimentan grandes dosis de racismo, amén de ofrecer una solución que despersonaliza el sistema judicial penal en su conjunto, o lo que es lo mismo, que favorece la exclusión subjetiva de la aplicación personal de la pena (Tonry, 1996, pp. 72-75; Christie, 1993, p. 144.).

Para evaluar su aplicación se fueron configurando las denominadas sentencing commissions, que no solo establecían, modulaban etc., los estándares para dictar sentencias condenatorias, sino que tenían la función de desarrollar investigaciones, monitorear el funcionamiento de la aplicación de las penas y, a su vez, analizar el impacto en la superpoblación carcelaria. En cada uno de los estados existían variaciones en los criterios y su aplicabilidad, si bien es indudable que la influencia de las experiencias de unos y otros estados les ha servido para, cada vez más, ir acercando las soluciones o criterios del sistema alfanumérico que se ofrecía.

La incorporación de estos criterios instrumentales provocaba consecuencias economicistas medibles desde los parámetros de la aplicabilidad del análisis económico del derecho que, desde su irrupción en la Escuela de Chicago, proyectaba su ideología y su visión economicista también en la justicia, sin que escapara de esa interpretación la justicia penal. Así, se fue no solo controlando desde las Comisiones antes citadas la aplicabilidad de estos criterios, sino también se fue haciendo necesario considerar el efecto económico que estas guidelines generaban, a saber, de qué forma alteraban o afectaban a la población carcelaria. Importaba el "coste" que su aplicación suponía. Es por ello que se sugería la incorporación de estándares que permitieran valorar esta cuestión, es decir, que evitaran la necesidad de mayores fondos presupuestarios para hacer frente a una superpoblación carcelaria que iba en aumento (Reitz \& Reitz, 1997, p.17), debido a esa propulsión a condenar por la aplicación de las guidelines. De este modo se valoraban dos elementos y su equilibrio, a saber, las ventajas de la aplicación en las condenas de las guidelines y las desventajas económicas - gastosque podría implicar el aumento lineal de condenas con privación de libertad y, por ende, aumento de la población penitenciaria.

Es más, ineludiblemente, el sistema de aplicación de las guidelines favorece el denominado derecho penal de autor. Se favorece la gravedad de la condena no por los hechos cometidos, sino con base en circunstancias personales y especialmente en los elementos de su personalidad (Cullen \& Gilbert, 1989, p. 81). Esta alteración se hizo sentir aún más, si cabe, cuando aparecieron las denominadas mandatory penalties, que venían a imponer penas de prisión muy altas cuando los hechos, referidos a drogodependencia, delitos sexuales, etc. Entonces, se entendía mecánicamente la obligatoriedad de su aplicación, y se favorecía con ello un endurecimiento en las condenas. En esta línea se encuentra, a título de ejemplo, la consideración de la regla de la three strikes and you're out, cuya aplicación era automática cuando se trataba de reincidentes, lo que suponía una condena automática más grave que cuando se tratare de delincuentes habituales.

El efecto de estas reglas o condicionantes a la hora de determinar la condena de una persona no solo producía efectos procesales, sino que se presentaba 
como un buen instrumento de manipulación pública por los políticos, que las utilizaban en las campañas, con promesas de seguridad ciudadana y orden público, condenas y encarcelamientos masivos. Cuestión diversa es el equilibrio que supuso la visión economicista de su aplicación en el contexto estadounidense en general, propiciando a este respecto una menor aplicabilidad en la práctica, como consecuencia de la necesidad de evitar los gastos propiciados por el aumento de presos en las instituciones penitenciarias. Es por ello que, como algún autor ha señalado, efectivamente se utilizaba a modo de lemas simbólicos en el debate político. Ello no es óbice a que no hay que perder de vista que el simbolismo penal "lejos de ser inerte, también ayuda a crear realidad" (Zysman, 2012, p. 300). Una realidad que en absoluto comporta una mejora ni de las relaciones ni de la sociedad ni de las personas mismas.

Con todo no debe olvidarse que la incorporación de estas reglas, sean optativas o sean obligatorias, reflejan una indudable desconfianza de los políticos sobre los jueces y sobre la justicia en general. Se vende control y seguridad también en el contexto de las decisiones judiciales, argumentándose con ello que se están otorgando mayores dosis de predictibilidad, certeza y seguridad a la ciudadanía. Todo ello obviamente cercenando la capacidad decisora del juez.

Estos estándares o criterios de aplicación por los jueces en las decisiones condenatorias, que alteran la capacidad del mismo y vacían la discrecionalidad judicial en EE. UU., han sido seguidos, cada vez más, en numerosos países, denominándoles de forma diversa, pero incidiendo en esa tendencia a cercenar la capacidad decisora del juez. Es más, la situación, lejos de quedarse estancada, ha ido avanzando estrechamente vinculada a la cuarta revolución industrial o el 4.0., que lejos de moverse tan solo en el ámbito de la empresa y en el sector económico, ha alcanzado igualmente a la justicia en general y a la justicia penal en particular.

En este sentido, y en línea con los principios de la cuarta revolución industrial, interesa que la justicia pueda alcanzar lo que se le achaca como uno de los grandes males: la predictibilidad de las sentencias. La absoluta ausencia de esta nota ha venido afectando el funcionamiento de la justicia, argumentándose que la disparidad de criterios, la no predictibilidad de los resultados y los gastos inútiles que todo ello ha reportado son muestras de la necesidad de un cambio, en aras de alterar ese modus operandi del aparato de la justicia. $\mathrm{O}$, lo que es lo mismo, se trata de incorporar sistemas que permitan evaluar, desde la predictibilidad de los resultados, si es conveniente o no acudir a un proceso judicial, a un arbitraje, a una mediación o mantener una posición pasiva, evitando no solo el mal empleo del tiempo, de los medios y del costo, sino también la carga psicológica que supone mantener esa suerte de pie de guerra que conlleva ineludiblemente la litigación y los mecanismos de confrontación de las personas.

Desde esa visión, muy probablemente, e influida de forma especialmente importante por las nuevas maneras de diseño, gestión y distribución de la industria del 4.0., claramente vinculada a los avances tecnológicos, surgieron los sistemas computacionales que permiten la predictibilidad de las sentencias. Así, en la década de los años noventa del siglo pasado comenzaron a realizarse modelos de muestreo estadístico de sentencias penales, a partir de las cuales sea posible predecir los resultados confirmatorios o revocatorios de las sentencias que se dictaren en sede de apelación. Interesante fue el proyecto lanzado en relación con la Corte de Apelaciones de Nueva Zelanda en procesos penales seguidos por la comisión de delitos sexuales: se valoró el perfil del ofensor y las circunstancias en las que se cometieron Ios delitos, elementos que alimentaban el sistema computacional, y permitían llegar a la conclusión de que el muestreo estadístico era un método útil para predecir el éxito de una posible apelación y, por ende, la utilidad o no de su planteamiento, lo que evita acciones penales innecesarias, amén de costosas (Simester \& Brodie, 1993, pp. 49-60).

Estos sistemas computacionales son instrumentos muy efectivos en determinados sectores - sin duda alguna - especialmente en sede de proceso civil o de arbitrajes, por cuanto permiten trabajar con elementos suficientes que facilitan detectar si es conveniente iniciar un proceso judicial o mejor acudir a un arbitraje y, en todo caso, las líneas-fuerza para preparar la defensa de quien se encuentra afectado por el conflicto. Su aplicación en 
ámbitos económicos refleja que su efectividad lleva a evitar esfuerzo, tiempo, y dinero. Es por ello que estas plataformas se integran muy bien en un mundo global de conflictividad mercantil, económica, internacional. Estos métodos permiten a los grandes despachos y a los lobbies económicos internacionales saber cómo moverse a la hora de preparar una posible estrategia, esto es, según quién puede ser mediador o árbitro o juez, tipo de nacionalidad, cuantía, materia compleja o simple, tiempos, etc. Es la aplicación de la informática y las tecnologías a la búsqueda de una homogeneidad y previsión de los resultados que pueden obtenerse en el marco de un litigio (Guzmán, 2017, p. 82).

Ciertamente, si bien en el mundo privado y económico la aplicabilidad de estos métodos computacionales que favorecen la predictibilidad no plantea dudas, y se presenta como un método de diagnóstico que indudablemente comporta enormes dosis de eficiencia y eficacia de las relaciones jurídicas y, sobre todo, de la gestión de posibles diferencias y conflictos existentes, la traslación de estos métodos a sede procesal penal plantea otros interrogantes, bastante más complejos y en ciertos casos más peligrosos. Hablar de predictibilidad criminal es indudable que puede alimentar un discurso peligroso cuando se construye sobre la base de la predeterminación de criterios de predisposición de actuación criminal.

En este sistema se trabaja con criterios que se refieren a la configuración de grupos sociales, excluyendo a aquellos en los que concurren esos riesgos (Rose, 2002, pp. 179-205); estereotipos, compartimentos estancos sociales, presunciones negativas, prejuicios, y un largo etcétera que indudablemente favorecen y alimentan el discurso del odio, el racismo, la xenofobia, la exclusión y la segregación. Este discurso, lejos de favorecer las relaciones personales y sociales y trabajar por la paz social, no hace sino aportar más dureza, más violencia, menos igualdad y más injusticia social. Se habla de componentes para incorporar en el sistema computacional para el análisis y la previsión de esa predictibilidad criminal, como la raza, el género, la edad, los ingresos, la educación, el estado laboral en que se encuentra, si es persona integrada familiarmente, su salud, si lleva vida desorganizada, donde nació, etc. (Chappell,
Monk-Turner \& Payne, 2017, pp. 262-270). EN suma, todos ellos se integran en el programa computacional para determinar "comportamientos futuros", algo así como una posible previsión de su culpabilidad y, sobre todo, de su futurible comportamiento delictivo. Se les considera como componentes esenciales del sistema computacional que permiten, en el modelo de justicia americano, que la policía pueda garantizar la quality of life de los ciudadanos americanos o, lo que es lo mismo, que segregan a quienes puedan alterar esta calidad de vida por tener una predisposición a quebrarla, al ser "potenciales" delincuentes. Un discurso muy peligroso que trabaja desde la tecnología con datos que permiten avizorar esos posibles comportamientos futuribles. Con ello se fundamenta la adopción cada vez más de la denominada tutela preventiva, esto es, actuar ex ante una previsible conducta que probablemente se cometerá por determinadas personas que reúnen condiciones aparentemente favorecedoras de una comisión de hechos delictivos.

Este modelo representa una clara manifestación de la revolución industrial del 4.0. y el cambio de modus operandi de la justicia penal, en cuanto estos sistemas computacionales se presentan como la vía para equilibrar los costes de la justicia con las respuestas que la misma puede ofrecer o, lo que es lo mismo, en materia penal se favorece una reestructuración de los activos policiales y de la optimización de su actividad en aras de conseguir resultados más satisfactorios para la sociedad en general.

Ahora bien, es indiscutible que este modelo computacional introduce un componente perverso que genera una ruptura del fundamento esencial que mueve la justicia penal, esto es, se olvida que, detrás de una sentencia penal, hay siempre personas con derechos fundamentales. Estos sistemas computacionales no escapan de una dura crítica que consideramos imprescindible realizar: la predictibilidad se eleva a la cúspide de los resultados, pero a costa de las personas o, mejor si cabe, de determinadas personas. El ejemplo lo hemos visto en algunos estados americanos a través de la elaboración de programas informáticos que determinan los altos índices de probabilidad de que el acusado (negro o latino, hombre, de clase social muy baja) vuelva a delinquir, por lo que ello estimula una condena con 
una pena más grave. Resulta estremecedor que estos programas informáticos se conviertan en informantes vinculantes para el juez a la hora de dictar la sentencia y fijar la calidad y cantidad de la pena; obviamente, estos programas se presentan como instrumentos infalibles para garantizar la seguridad en la sociedad (Guzmán, 2017), una seguridad que falsamente puede alcanzarse y desde luego con el coste elevadísimo de la violación de la presunción de inocencia, del derecho de defensa, del derecho con todas las garantías, la igualdad de todos ante la ley y un largo etcétera que la inteligencia artificial "todavía" no ha integrado.

Es por todo ello, que compartimos la opinión de Guzmán Fluja cuando considera que, muy a pesar del índice de acierto predictivo que presentan estos programas computacionales, no puede olvidarse el posible margen de error que también existirá. Es más, como apunta textualmente este autor

a) se impone una pena añadida anticipada sin más base que la más o menos alta probabilidad de que se pueda volver a delinquir y, aunque eso fuera cierto (quiere decirse 100\% probable), sólo una vez cometidos esos "nuevos" delitos podría procederse a juzgar al sujeto $y$, en su caso, imponerle la pena correspondiente; b) para el caso de que, una vez excarcelado, el sujeto no volviera a delinquir, y fallase así la predicción del programa informático, entonces la medida sería absolutamente injustificable y contraria a los derechos más elementales de la persona porque habría habido una pena sin delito en contra de los más elementales principios del derecho penal y procesal penal (2017).

En ciertos casos, podríamos trabajar con los modelos computacionales in bonam parte a saber, en aquellos supuestos en los que se deriva un bajo índice o nulo riesgo de volver a cometer un delito en el futuro, debe considerarse a efectos de atenuación de la condena.

En suma, creemos que la aplicación de los programas informáticos para trabajar la predictibilidad de las sentencias penales, que favorece el endurecimiento de las penas, el derecho penal de autor, la segregación y el quebrantamiento del principio de igualdad de todos los ciudadanos ante la ley, debe cuestionarse, a saber, si este va a ser un método de empleo común en los ordenamientos jurídicos, habrá que dotar de los debidos mecanismos de valoración e impugnación de los datos que se incorporan al sistema informático (lo que no es sino cuestionar la posición de quien alimenta el modelo computacional), pudiendo discutir además los resultados que se alcancen. Es decir, los sistemas programados informáticamente pueden favorecer a la sociedad en determinados ámbitos, indudablemente, pero cuando se trata de los derechos fundamentales de la persona, de la libertad y, sobre todo, de la consideración de la persona como tal, deben otorgarse medios que permitan cuestionar el pensamiento del sistema o, lo que es lo mismo, los datos incorporados, amén de los resultados que los mismos producen.

\subsubsection{Machine learning, Deep learning, juez-robot}

Expuestos algunos ejemplos de la impronta de la inteligencia artificial en el mundo de la justicia o, lo que es lo mismo, de la incorporación de la inteligencia computacional o inteligencia a través de las máquinas, que imitan las funciones cognitivas de las mentes humanas en la misma, los avances hacia un perfeccionamiento de la máquina inteligente no cesan, de modo que, si bien la inteligencia artificial es la ciencia que se ocupa de diseñar máquinas que emulan el pensamiento humano, emergen nuevos conceptos, como machine learning que, vinculado estrechamente al área de la inteligencia artificial, la supera, al desarrollar programas informáticos capaces de aprender por sí mismos y realizar, entre otras acciones, las predicciones a las que nos hemos referido supra. La machine learning se aplica mediante la técnica del deep learning, un tipo específico de algoritmos conocidos como redes neuronales, que son los modelos matemáticos que emulan el comportamiento estructural del cerebro humano, tomando como base la interacción entre las neuronas (Sucasas, 2018, p. 74).

Estos avances de la inteligencia artificial permiten aunar los esfuerzos de la robótica con otras áreas, que incorporan elementos de la psicología, la neurociencia, la lingüística, la genética, la pedagogía, la logopedia, la matemática y muchos otros, que trabajan conjuntamente en la elaboración de máquinas inteligentes que permitan llevar a cabo razonamientos automáticos, demostración de teoremas, sistemas de expertos (en medicina, en 
ingeniería, en el ámbito castrense y también en el mundo jurídico, entre otros), el aprendizaje, etc. Se buscan soluciones desde la máquina, pero con el sentido común humano. Esa búsqueda del pensamiento humano exige la aplicación de unas reglas de juicio que guíen la toma de decisiones; son las denominadas reglas heurísticas (ante un tipo de problema permite seleccionar las posibles bifurcaciones que podemos plantearnos ante un camino lleno de ramificaciones, lo que restringe por ello las posibles soluciones) que en absoluto son infalibles. Estas reglas heurísticas son indudablemente un mecanismo de manipulación inteligente.

Con ellas se avanza en la inteligencia artificial, tratando de combinar en los programas computacionales estructuras de datos y procedimientos de interpretación con diferentes lenguajes para diferentes campos de aplicación, ejemplo del cual es el software. Los resultados son visibles en numerosas áreas (posibilidad de realizar diagnósticos médicos, preparación de estrategias militares, consultas de los consumidores, evaluaciones económicas, etc.). En gran medida todos ellos conectan con los diversos tipos de inteligencia artificial (Russell \& Norvig, 2009), entre los que se encuentran: sistemas en los que se emula el pensamiento humano, como sucede con las redes neuronales artificiales, lo que favorece la toma de decisiones, la resolución de problemas y el aprendizaje (un razonamiento basado en casos); en otros casos son sistemas que permiten actuar como humanos, imitando su comportamiento, como sucede con el robot; otros sistemas que emulan el pensamiento lógico racional del ser humano como la creación de sistemas expertos -que infieren una solución a través del conocimiento previo del contexto en que se aplica y hace uso de ciertas reglas o relaciones o, lo que es lo mismo, la necesidad de definir el dominio sobre el que versará el sistema, definición del o de los problemas, integración del equipo interdisciplinario, identificación de expertos cuyo conocimiento sea modelado, adquisición de conocimiento experto, representación del conocimiento experto, programación, validación del prototipo, implementación final, mantenimiento y actualización$y$, finalmente, aquellos sistemas que emulan la forma racional del comportamiento humano como sucede con los agentes inteligentes (conductas inteligentes de artefactos). Ejemplos los encontramos diariamente en los videojuegos, el ajedrez computacional, los sistemas de lenguaje, en los avances médicos y terapéuticos (un exponente muy interesante fue el que se desarrolló en 2009 como sistema terapéutico para detectar emociones e interactuar con niños autistas).

Estos avances inteligentes pretenden la imitación del cerebro de la persona en todas sus funciones, si bien no parece que la situación vaya a estancarse, dados los experimentos realizados ya para conseguir que la máquina no solo piense por sí sola, sino que pueda tener su pensamiento propio superando las capacidades humanas. Y esta situación parece ir aproximándose cada vez más al mundo de la justicia. Podemos citar, a este respecto, la incorporación del juez robot en un sector como el de los conflictos en materia de consumo, por el enorme impulso recibido a estos efectos desde la Unión Europea (Directiva 2013/11/UE del Parlamento Europeo y del Consejo y el Reglamento (UE) N. 524/2013, del Parlamento Europeo y del Consejo, de 21 de mayo de 2013), lo que da lugar a la consolidación de las Online Dispute Resolution (ODR) en materia de consumo. Las peculiaridades propias de los conflictos sobre consumo pueden favorecer estos mecanismos en los que los programas informáticos desempeñan un interesante aporte en la resolución de conflictos, todo, y que es la robotización de la solución del conflicto (la máquina inteligente), estandarizando las respuestas de acuerdo con un programa apropiado para ello. La máquina inteligente sustituye en la toma de decisiones al órgano decisor, resolviéndose, así, de modo ágil, rápido, económico y predecible los conflictos que puedan suscitarse en este sector.

El camino continúa y resulta especialmente significativo observar la paulatina extrapolación de estas iniciativas de robotización judicial a la sede penal. La incógnita es la de valorar si efectivamente el juez robot puede llegar a sustituir al juez humano en el proceso penal. A priori entiendo-dejando fuera un perfeccionamiento de la máquina que supere al hombre, lo que podría ser altamente peligroso para la especie humana-, que extrapolar estas iniciativas de robotización judicial a la sede penal llevaría a la liquidación del proceso penal, al convertir este en un expediente automatizado que impediría el ejercicio de los derechos reconocidos a quienes son 
sujetos del proceso penal; mermarían las garantías de defensa y propulsarían una mecanización judicial que, cuando menos, chocaría con el proceso lógico jurídico de razonamiento judicial que aplica la norma al caso concreto, al sujeto concreto y bajo unas circunstancias concretas, modulando y justificando esta modulación en la motivación de los hechos probados. Se cuestionaría no solo la inteligencia humana, sino cómo esta se aplica en el ámbito del derecho penal para determinar, desde la mirada interior de nosotros mismos, para cuestionarnos acerca de cuándo y cómo tenemos derecho de castigar a otros (Whitman, 2008, p. 7), lo que se perdería con la aplicación del sistema computacional inteligente que propiciaría la mecanización de las respuestas penales, aun cuando pudiera también el juez-robot motivar sus decisiones.

En estos momentos, no deja de ser muy inquietante el avance de la robotización judicial y las perspectivas de futuro en sede procesal penal. Se abriría una nueva vía, pero desde luego no el proceso penal, que quedaría liquidado desde la aplicabilidad de la máquina inteligente. Los derechos y las garantías en el proceso penal no son una mera declaración formal de principios, sino que son los pilares sobre los que debe moverse el modelo de Estado de derecho, encarnan la legitimidad del propio sistema procesal y, por tanto, cualquier avance que la revolución industrial y tecnológica del 4.0. pueda propiciar en la justicia penal, debe contar con una conditio sine qua non: nunca los avances de la robotización de la justicia pueden hacerse a costa de los derechos y las libertades de los ciudadanos.

Quizás en el futuro la inteligencia artificial supere el pensamiento humano crítico, sus imperfecciones y sea capaz de equilibrar la libertad y la seguridad, si bien deberá tenerse claro quién alimenta el pensamiento del robot juez o quién construye el pensamiento que deba retroalimentarse por sí mismo; esto es, quién construye el pensamiento global, uniforme, que controla todo y a todos. Se habla incluso de un avance mayor en inteligencia artificial que es, no ya la creación de un robot judicial que responda a un sistema diseñado desde la mente humana para que, en función de unos criteria, termine decidiendo, sino que pretende un paso más, que sea la misma máquina la que termine creando su propio pensamiento (como se avanzó con algunos modelos como Hiro o Sophie) y, por ende, su capacidad sui generis de resolver en sede penal. Y que ese pensamiento permita también a la máquina individualizar la pena, incorporando las variables personas, espacios, circunstancias, etc. Es posible que veamos un modelo computacional que supere las falencias de la mente humana y que permita mejorar la capacidad de decisión de la mente humana, incluso construyendo decisiones más justas. Podría llegarse a ese modelo de justicia feliz, al estilo de la obra de Un mundo feliz de Huxley, si bien habrá que incorporar respuestas igualmente frente a la posible responsabilidad que pueda generar la máquina, algo así como la creación del estatuto de la persona electrónica y su necesidad de poder responder de sus actuaciones.

Concluimos afirmando que aceptamos el reto que en su día planteó Drew Faust, la primera mujer presidente de la Universidad de Havard, de abrir las mentes; así seremos capaces de imaginar un mundo distinto. Un mundo que se avizora tecnológico de última generación, en el que se conviva con máquinas inteligentes que colaboren, pero también sustituyan las tareas que en la actualidad solo las mentes humanas pueden realizar. Aceptamos el reto, admitimos la evolución, la innovación y la sofisticación tecnológica y la asumimos desde una visión positiva. Esto es, tan solo si la inteligencia artificial y la máquina inteligente se convierten en instrumento de creación de un mundo mejor, un mundo en el que se erradique la desigualdad, la pobreza y la falta de oportunidades. De lo contrario, la máquina inteligente destruirá el mundo de los humanos. 


\section{Referencias}

Barona Vilar, S. (2011). Mediación penal: Fundamento, fines y régimen jurídico. Valencia: Tirant lo Blanch.

Barona Vilar, S. (2017). Proceso penal desde la Historia: Desde sus orígenes a la sociedad del miedo. Valencia: Tirant lo Blanch.

Barona Vilar, S. (2018). Justicia Penal: Globalización y Digitalización. Santiago, Chile: Thomson Reuters.

Braithwaite, J. (2003). Principles of Restorative Justice. En J. Roberts, A. Von Hirsch, A. E. Bottoms, K. Roach \& M. Schiff (Eds.). Restorative Justice and Criminal Justice: Competing or reconcilable paradigms? (pp. 1-20). Portland: Hart Publishing.

Chappell, A. T., Monk-Turner, E. \& Payne, B. K. (2011). Broken Windows or Window Breakers: The Influence of Physical and Social Disorder on Quality of Life. Justice Quarterly, 28(3), 522-540.

Christie, N. (1993). La industria del control del delito (¿La nueva forma del holocausto?). Buenos Aires: Del Puerto.

Cullen, F.T. \& Gilbert, K. E. (1989). Reaffirming Rehabilitation. Cincinatti: Anderson Publ.

Guzmán Fluja, V. (2017). Sobre la aplicación de la inteligencia artificial a la solución de conflictos. En S. Barona Vilar (Ed.). Justicia civil y penal en la era global (67-122). Valencia: Tirant lo Blanch.

Hobsbawm, E.J., (2012), Guerra y paz en el Siglo XXI. Barcelona: Booket

Plant, R. (2016). Friedrich August von Hayek: Der (neo-)liberale Staat und das Ideal des Rechtsstaats. En Th. Biebricher (Ed.). Staatsverständnisse (75-98) Baden-Baden: Nomos.

Reitz, K. R. \& Reitz, C. R. (1997). American Bar Association Adopts New Sentencing Standards. En M. Tonry \& K. Hatlestad (Eds.). Sentencing Reform in Overcrowded Times: A Comparative Perspective (17-19) New York/Oxford: Oxford University Press.

Rich, W.D., Sutton, L.P., Clear, T.R. \& Saks, M. (1982). Sentencing by Mathematics: An Evaluation of the Early Attempts to Develop and Implement Sentencing Guidelines. National Center for State Courts.

Rose, W. (2002). Crimes of Color: Risk, Profiling and the Contemporary Racialization of Social Control. International Journal of Politics, Culture and Society, 16 (2), 179-205.

Russell, S. \& Norvig, P. (2009). Artificial Intelligence: A Modern Approach file:///C:/Users/74740413/Downloads/ a154ffbcec538a4161a406abf62f5b76-original.pdf [Fecha de consulta 24 de abril de 2019].

Schwab, K. (2018). La cuarta Revolución Industrial (4ª ed.). Barcelona: Debate.

Simester, D. I. \& Brodie, R. J. (1993). Forecasting criminal sentencing decisions. International Journal of Forecasting 9(1), 49-60.

Stegler, M. B. (2003). Globalization: A Very Short Introduction. Oxford: Oxford University Press.

Sucasas, A. L. (2018). La inteligencia artificial no va a ser más inteligente que nosotros. Revista Retina, El País,

(2). Recuperado de https://retina.elpais.com/retina/2018/02/19/tendencias/1519034268 083764.html [Fecha de consulta 24 de abril de 2019].

Tonry, M. H. (1996), Sentencing Matters. New York, Oxford: Oxford University Press.

Whitman, J. Q. (2008). The Origins of Reasonable Doubts. Yale: Yale University Press.

Zysman Quirós, D. (2012). Sociología del castigo: Genealogía de la determinación de la pena. Buenos Aires: Didot. 